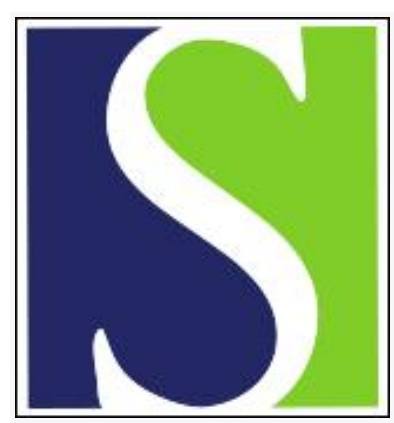

Scand J Work Environ Health 1986;12(2):149-153

https://doi.org/10.5271/sjweh.2164

Issue date: Apr 1986

Correlation of xylene exposure and methyl hippuric acid excretion in urine among paint industry workers.

by Lundberg I, Sollenberg J

This article in PubMed: www.ncbi.nlm.nih.gov/pubmed/3726497

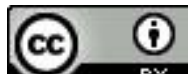




\title{
Correlation of xylene exposure and methyl hippuric acid excretion in urine among paint industry workers
}

\author{
by Ingvar Lundberg, MD, Jan Sollenberg, $\mathrm{PhD}^{1}$
}

\begin{abstract}
LUNDBERG I, SOLLENBERG J. Correlation of xylene exposure and methyl hippuric acid excretion in urine among paint industry workers. Scand $J$ Work Environ Health 12 (1986) 149-153. Different calculations of methyl hippuric acid excretion in urine were correlated to the time-weighted average (TWA) of the xylene exposure of a complete workday for 40 paint industry workers exposed to 12 different solvents. The 8-h TWA xylene exposure varied between 0 and 865 (median 69) $\mathrm{mg} / \mathrm{m}^{3}$. The amount of methyl hippuric acid excreted in about $24 \mathrm{~h}$ showed only a slightly higher linear correlation to the xylene exposure than the amount of methyl hippuric acid excreted per hour during the latter part of the workshift among the 37 subjects exposed to TWA xylene air concentrations of $0-200 \mathrm{mg} / \mathrm{m}^{3}$. It was concluded that the methyl hippuric acid excretion rate during the latter part of the workshift can be used for crude xylene exposure categorizations.
\end{abstract}

Key terms: biological monitoring, solvent exposure.

Several organic solvents have biotransformation products which can be measured in urine and used for estimating occupational exposure. Trichloroacetic acid and trichloroethanol are commonly used as indicators of trichloroethylene exposure. Mandelic acid, sometimes in combination with phenylglyoxylic acid, is a rather reliable and commonly used estimator of styrene exposure (1).

Concerning xylene, the three isomers, o-, m-, and p-xylene are excreted in urine mainly as the three corresponding methyl hippuric acids. These acids do not normally occur in urine, and different calculations of the total urinary excretion of methyl hippuric acid (MHA) have been found to be useful estimators of the net exposure to the mixture of isomers found in commercial xylene $(4,8,12)$. However, the application of the urinary monitoring of MHA in occupational health practice seems to be limited, and surprisingly few studies have been reported on this subject. Thus there is a need to evaluate MHA excretion as an indicator of xylene exposure in the work environment.

During the last 25 years xylene has been a major component of most solvent-based paints manufactured in Sweden, and accordingly workers in the paint industry have been heavily exposed to this solvent (15). The purpose of this investigation was to study, with a reasonably simple sampling regime, the correlation between xylene air exposure and different calculations of urinary MHA excretion.

\footnotetext{
Research Department, National Board of Occupational Safety and Health, S-171 84 Solna, Sweden.
}

Reprint requests to: Dr I Lundberg, Research Department, National Board of Occupational Safety and Health, S-171 84 Solna, Sweden.

\section{Subjects and methods}

\section{Subjects}

Forty workers ( 35 men, 5 women) employed in seven different paint factories participated in the study. They were 22-64 (median 57) years of age. In all, 38 participants had been employed for at least seven years, while two male "cleaners" with outstandingly high exposures to xylene had been employed in the paint industry for 0.2 and 0.4 years, respectively.

The reported heights of the subjects varied between 164 and $189 \mathrm{~cm}$, and their reported body weights were between 51 and $118 \mathrm{~kg}$. The reported median alcohol consumption was 62 (range $0-304$ ) g of alcohol/week. Nine subjects had taken some kind of pharmaceutical at least three times a week during the last three weeks. Preshift blood samples were obtained in the morning from all the participants, and serum was later analyzed for gamma glutamyl transferase (GT) as a crude indicator of microsomal enzyme induction. The details of these determinations have been presented elsewhere (6).

\section{Exposure}

Air from the breathing zone of every subject was collected with battery-driven syringes, each representing about 30 min of exposure, during a complete workday. The contents of the syringes were analyzed with two AID $^{\circledast}$ portable gas chromatographs with flame ionization detectors. Steel columns were used (length $2 \mathrm{~m}$, internal diameter $0.32 \mathrm{~cm}$ ), and they were packed with Chromosorb C (60-80 mesh) coated with $2 \%$ Carbowax 400 or Chromosorb WHP (80-100 mesh) coated with $10 \%$ DC 200 . The column temperatures were 60 and $100^{\circ} \mathrm{C}$, respectively. This method for air sampling and measuring solvent air concentrations showed good validity and reproducibility concerning 
toluene and styrene air concentrations of 200 and 260 $\mathrm{mg} / \mathrm{m}^{3}$, respectively (7). The exposure measurements were performed on a Tuesday, Wednesday, or Thursday of an ordinary workweek.

Altogether 12 solvents were detected in the air. The workers were exposed to three to nine solvents (median seven) each. The main exposure was usually to xylene, but the xylene fraction of the total solvent exposure varied on a weight basis between 0 and $87 \%$. Table 1 shows that the subjects exposed to a solvent mixture containing more than $50 \%$ xylene were also the most exposed to this solvent on the average. However, those exposed to solvent mixtures with $25-49 \%$ xylene were exposed to xylene air concentrations almost as high. The two most heavily exposed subjects had less than $50 \%$ xylene in their solvent mixture.

Personal protection equipment was not used. Most of the workers performed physiologically light work during the whole workday.

\section{Urinary sampling and analysis}

Before starting work on the day of the investigation, all the participants were asked about their time of urination in the morning. They were given two plastic bottles for urine collection and were instructed that all urine voided before the lunch break should be collected in the first bottle and that all urine voided in the afternoon should be collected in the second. On leaving the workplace for lunch and after work in the after-

Table 1. Xylene fraction of the solvent mixture $(\mathrm{g} / 100 \mathrm{~g}$ of solvents).

\begin{tabular}{lccc}
\hline $\begin{array}{l}\text { Xylene fraction } \\
\text { of solvent } \\
\text { mixture } \\
(\mathrm{g} / 100 \mathrm{~g} \text { solvent })\end{array}$ & $\begin{array}{c}\text { Exposed } \\
\text { subjects } \\
(\mathrm{N})\end{array}$ & $\begin{array}{c}\text { Median } \\
\text { xylene } \\
\text { exposure } \\
\left(\mathrm{mg} / \mathrm{m}^{3}\right)\end{array}$ & $\begin{array}{c}\text { Range } \\
\text { of xylene } \\
\text { exposure } \\
\left(\mathrm{mg} / \mathrm{m}^{3}\right)\end{array}$ \\
\hline$\geq 50$ & 17 & 92 & $14-273$ \\
$25-49$ & 12 & 74 & $40-865$ \\
$0-24$ & 11 & 13 & $0-201$ \\
\hline
\end{tabular}

Table 2. Regression analysis for 8-h time-weighted average xylene exposure versus different methyl hippuric acid (MHA) excretion calculations, with coefficients of correlation (r) and standard deviations about the regression lines (s), for the entire group and for the entire group with the three most heavily exposed subjects excluded.

\begin{tabular}{|c|c|c|}
\hline MHA calculation & $\begin{array}{l}\text { Linear regression } \\
\text { function }(N=40)\end{array}$ & $\begin{array}{l}\text { Linear regression } \\
\text { function }(N=37)\end{array}$ \\
\hline $\begin{array}{l}\mu \mathrm{mol} \times \mathrm{kg} \text { body } \\
\text { weight }-1 \\
\text { excreted in } 24 \mathrm{~h}\end{array}$ & $\begin{array}{l}y=0.186 x+11.3 \\
(r=0.87, s=16.7)\end{array}$ & $\begin{array}{l}y=0.352 x-0.17 \\
(r=0.84, s=13.6)\end{array}$ \\
\hline $\begin{array}{l}\mu \mathrm{mol} \times \text { hour }^{-1} \times \mathrm{kg} \\
\text { body weight } \\
\text { excreted during } \\
\text { the latter part } \\
\text { of the workshift }\end{array}$ & $\begin{array}{l}y=0.0172 x+0.977 \\
(r=0.85, s=1.73)\end{array}$ & $\begin{array}{l}y=0.0327 x-0.056 \\
(r=0.81, s=1.45)\end{array}$ \\
\hline $\begin{array}{l}\mu \text { mol } \times 1^{-1} \times \mathrm{kg} \\
\text { body weight } \\
\text { excreted during } \\
\text { the latter part } \\
\text { of the workshift }\end{array}$ & $\begin{array}{l}y=0.224 x+13.6 \\
(r=0.85, s=22.0)\end{array}$ & $\begin{array}{l}y=0.373 x+3.96 \\
(r=0.76, s=19.2)\end{array}$ \\
\hline
\end{tabular}

noon, they were instructed to try to empty the bladder. At the end of the workday they received a third bottle in which all urine voided until, and including, the next morning should be collected. The participants were told to note the time of every urination.

The volume and the density of the urine in each bottle was determined. A sample of urine from each bottle was kept frozen until the time of analysis. Both hippuric acid (HA) and total MHA were determined in the samples according to an isotachophoresis method with sufficient validity and reproducibility $(13,14)$. The practical MHA quantitation limit was $0.5 \mathrm{mmol} / \mathrm{l}$. Metabolite concentrations were corrected to the urine density of 1.018 .

\section{Statistical methods}

The relationship between xylene exposure and MHA excretion was studied by linear regression analysis.

\section{Results}

The MHA excretion was correlated to the 8-h timeweighted average (TWA) xylene exposure after adjustment for body weight. The body weight adjustment improved the correlation coefficients ( $r$ ) in all the calculations.

Regression functions were calculated with the metabolite as dependent and the exposure as independent variables. The total amount of MHA found in the three bottles (sampling time approximately $24 \mathrm{~h}$ ) showed a virtually identical correlation to xylene exposure $(r=0.87)$ as the metabolite excretion in the second bottle (sampling time approximately $4-5 \mathrm{~h}$ ) expressed as micromoles per hour $(\mathrm{r}=0.85)$ or micromoles per liter with density correction $(r=0.85)$. The regression equations are shown in table 2 , and a plot of xylene exposure versus metabolite excretion rate in the afternoon samples is depicted in figure 1a.

The values of the three men exposed to the highest xylene concentrations (more than $250 \mathrm{mg} / \mathrm{m}^{3}$ ) greatly influenced the slope of the regression lines. Their exposures were rather much heavier than those of the others, and they could therefore be regarded as unrepresentative single outliers. When they were excluded, the correlation coefficients and linear regression equations also shown in table 2 were obtained. The amount of MHA excreted in approximately $24 \mathrm{~h}$ showed the highest correlation to exposure $(r=0.84)$ but not much higher than the excretion in the afternoon expressed as micromoles per hour $(r=0.81)$. Figure $1 \mathrm{~b}$ shows a plot of xylene exposure versus excretion rate with the three outliers excluded.

Exclusion of the five women did not change the coefficients, and the correlations for any subgroup of exposure (table 1) were not substantially different from those of the whole group. Age did not seem to influence the correlations and neither did stated alcohol or drug consumption nor the serum GT values. 

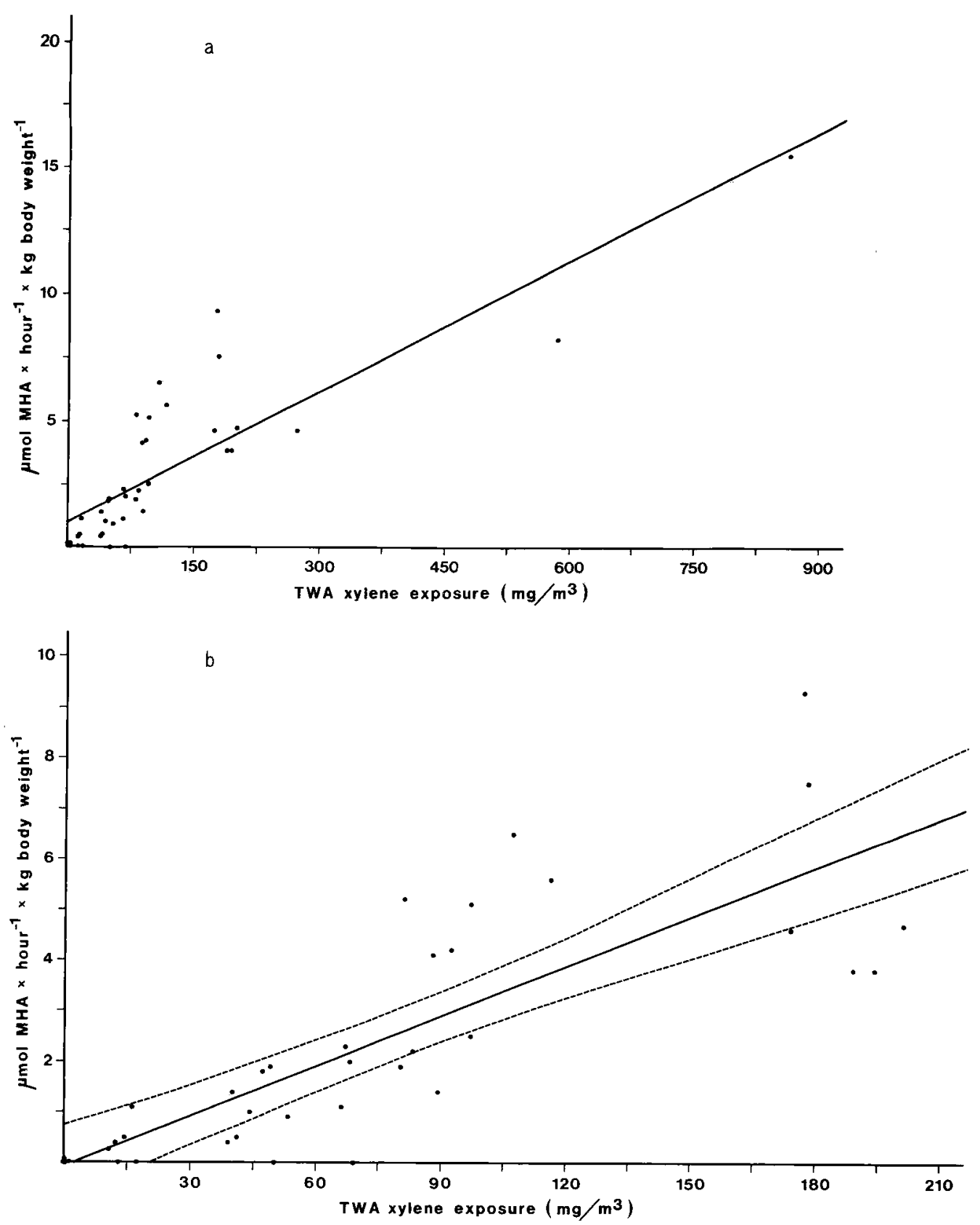

Figure 1. Amount of methyl hippuric acid (MHA) excreted per hour and kilogram of body weight during the latter part of the workshift as a function of the 8-h time-weighted average (TWA) xylene exposure of all the subjects (a) and of all the subjects except the three most heavily exposed, with $95 \%$ confidence limits for the mean MHA values (b).

Calculations with the MHA excretion as an indicator of total solvent exposure were also performed. In some instances high correlation coefficients were obtained. The linear regression function yielded a correlation coefficient of $0.82(\mathrm{~N}=25)$ for the afternoon MHA excretion rate versus the solvent hygienic effect, ${ }^{2}$

\footnotetext{
2 Hygienic effect was defined as the sum of the fractions of the respective hygienic standards that the exposure to each solvent represented.
}

among workers exposed to a solvent mixture with a xylene content of more than 25 weight $\%$ and below a hygienic effect of 1 . Similar coefficients were obtained when the total solvent exposure (in $\mathrm{mg} / \mathrm{m}^{3}$ ) was substituted for the hygienic effect. Very low correlations were found when the workers exposed to solvent mixtures with a xylene content of less than $25 \%$ were included.

The correlations between toluene exposure and different HA calculations were low, as expected. The 8-h 
TWA toluene exposures were very low (median 9, range $0-379 \mathrm{mg} / \mathrm{m}^{3}$ ), and no instructions to avoid food containing benzoic acid had been given.

\section{Discussion}

The highest correlation was obtained for xylene exposure versus the amount of MHA excreted in about $24 \mathrm{~h}$; this finding is in agreement with that of an earlier laboratory investigation (8). An almost perfect correlation $(r=0.99)$ between absorbed doses of xylene and the amount of MHA excreted in $24 \mathrm{~h}$ or per hour during the latter part of an 8-h exposure has been found in another laboratory study (12).

Urine collection over some period of time is theoretically superior to spot samples when metabolites with short half-times, like MHA, of rapidly metabolized chemicals, like xylene, are measured. However, 24-h metabolite sampling is often considered unreliable because of insufficient cooperation of the exposed subjects, and it seems hardly worth the effort as judged from the small differences between the correlation coefficients obtained in this study.

As an average estimate based on the results from several studies, Riihimäki has calculated that an $8-\mathrm{h}$ TWA xylene exposure of $435 \mathrm{mg} / \mathrm{m}^{3}(100 \mathrm{ppm})$ would yield an MHA excretion of around $14 \mu \mathrm{mol} \times \mathrm{kg}$ body weight ${ }^{-1} \times \mathrm{h}^{-1}$ during the last few hours of a workshift (10). The estimate of the same excretion calculation from the corresponding linear regression function in table 2, with the three most heavily exposed subjects excluded, is $14.2 \mu \mathrm{mol} \times \mathrm{kg}$ body weight ${ }^{-1} \times$ $\mathrm{h}^{-1}$, ie, the regression functions obtained in this study were in agreement with earlier findings.

In the only other field study available (4), Engström et al found a correlation coefficient of 0.80 between xylene exposure and MHA excretion per hour in urine collected during the last $4-5 \mathrm{~h}$ of a workshift, ie, results similar to our findings. However, they obtained higher correlations for MHA concentrations (corrected to density or adjusted to creatinine) in the same samples. An explanation can be that the large inter- and intraindividual variability in creatinine excretion and urine density may produce different correlations on different occasions merely due to chance, as shown concerning styrene exposure and mandelic acid excretion (16).

The three men most heavily exposed to xylene excreted just around $50 \%$ of the MHA that could be predicted from the regression equations obtained from the other workers. This finding might be due to chance since they were single outliers, but it might also reflect interference with the xylene disposition at some point in these workers. Glycine conjugation is probably the rate-limiting step in toluene and xylene biotransformation. The maximum conjugating capacity is around $200 \mu \mathrm{mol} / \mathrm{min}$ and is supposedly reached at a combined exposure to $270 \mathrm{ppm}$ of toluene and xylene when the work load is moderately heavy (ventilation $30 \mathrm{l} / \mathrm{min}$ ). Certain dietary factors might further reduce the availability of glycine for solvent conjugation (9). A worker who is exposed to high peaks of these solvents with simultaneous heavy work, combined with low exposure periods and simultaneous light work, would thus show a decreased MHA elimination over a longer time period as compared to a worker exposed to the same TWA concentration, but who had an even exposure and an even work load. The most heavily exposed men were exposed both to xylene and toluene, and their compined exposures to these solvents varied with 30 -min peaks up to 235,460 , and $560 \mathrm{ppm}$, respectively. Thus their capacity for glycine conjugation might have been exceeded for shorter time periods, since their work load was also somewhat heavier than normally during the peak exposures. However, as judged from their combined MHA and HA excretion during the afternoon (being about $40 \mu \mathrm{mol} / \mathrm{min}$ for the heaviest exposed worker), this capacity was far from reached during most of the afternoon. Xylene and toluene biotransformation may possibly also have been decreased by ethanol obtained from ethanol and ethylacetate exposure $(3,5,11)$. Whether the heavy methylene chloride exposure of two of the workers may have influenced the metabolic degradation of the solvents is not known, but toluene pretreatment has been shown to abolish completely the carboxyhemoglobin formation from methylene chloride in rats (2).

There was a considerable variation around the regression lines in all the correlations between air exposure and metabolite excretion variables in this study. This variation certainly reflects the interindividual variability in xylene disposition, but it might also reflect differences in uptake between the subjects due to differences in work load, ie, differences in internal dose.

The MHA excretion rate during the latter part of the workshift might be used for group determinations and for crude exposure categorizations in studies in which xylene exposure is predominant or is of particular interest. For workers in the paint industry MHA excretion might possibly in some instances be used as an indicator of total solvent exposure, but this procedure would require prior knowledge about the exposure conditions at each worksite where the method is applied.

\section{Acknowledgments}

The authors want to thank I-M Andersson and G Rosén, who performed the exposure measurements, and E-L Lundberg, who performed the methyl hippuric acid and hippuric acid analyses. We are grateful to M Söderholm for the typing and C Hogstedt for his comments on the manuscript.

This study was part of a research program on exposure and health hazards in the paint industry. It was financed by support from the Swedish Work Environment Fund. 


\section{References}

1. Aitio R, Riihimäki V, Vainio $H$, ed. Biological monitoring and surveillance of workers exposed to chemicals. Hemisphere Publishing Corp, Washington, DC 1984

2. Ciuchta HP, Savell GM, Spiker RC. The effects of alcohols and toluene upon methylene chloride-induced carboxyhemoglobin in the rat and monkey. Toxicol Appl Pharmacol 49 (1979) 347-354.

3. Dössing M, Baelum J, Hansen SH, Lundqvist GR. Effects of ethanol, cimetidine and propanol on toluene metabolism in man. Int Arch Occup Environ Health 54 (1984) 309-315.

4. Engström K, Husman K, Pfäffli P, Riihimäki V. Evaluation of occupational exposure to xylene by blood, exhaled air and urine analysis. Scand J Work Environ Health 4 (1978) 114-121.

5. Fernández J, Droz P. Absorption et élimination pulmonaire de l'acétate d'éthyle: Étude expérimentale sur des sujets humains. Arch Mal Prof Med Trav Secur Soc 35 (1974) 953-961.

6. Lundberg I, Håkansson M. Normal serum activities of liver enzymes in Swedish paint industry workers with heavy exposure to organic solvents. Br $\mathrm{J}$ Ind Med 42 (1985) 596-600.

7. Övrum P. Lösningsmedelsprovtagning i luft med motordrivna sprutor [Air sampling of solvents with motordriven syringes]. Arbetarskyddsstyrelsen, Solna 1981. (Undersökningsrapport 1981: 18).

8. Ogata M, Tomokuni K, Takatsuka Y. Urinary excretion of hippuric acid and $\mathrm{m}$ - or $\mathrm{p}$-methylhippuric acid in the urine of persons exposed to vapours of toluene and $\mathrm{m}$ - or p-xylene as a test of exposure. $\mathrm{Br} \mathrm{J}$ Ind Med 27 (1970) $43-50$.
9. Riihimäki V. Conjugation and urinary excretion of toluene and $\mathbf{m}$-xylene metabolites in a man. Scand $\mathbf{J}$ Work Environ Health 5 (1979) 135-142.

10. Riihimäki V. Xylene. In: Aitio A, Riihimäki V, Vainio $\mathrm{H}$, ed. Biological monitoring and surveillance of workers exposed to chemicals. Hemisphere Publishing Corp, Washington, DC 1984, pp 83-97.

11. Riihimäki V, Savolainen K, Pfäffli P, Pekari K, Sippel HW, Laine A. Metabolic interaction between m-xylene and ethanol. Arch Toxicol 49 (1982) 253-263.

12. Senczuk W, Orlowski J. Absorption of $m$-xylene vapours through the respiratory tract and excretion of m-methylhippuric acid in urine. Br J Ind Med 35 (1978) 50-55.

13. Sollenberg $\mathrm{J}$, Baldesten $\mathrm{A}$. Isotachophoretic analysis of mandelic acid, phenylglyoxylic acid, hippuric acid and methylhippuric acid in urine after occupational exposure to styrene, toluene and/or xylene. J Chromatogr 132 (1977) 469-476.

14. Sollenberg J, Phipps FC, Stringer B, Lowry LK. Determination of methylhippuric acid in human urine by high-performance liquid chromatography and by isotachophoresis. J Chromatogr 343 (1985) 419-423.

15. Ulfvarson U. Chemical hazards in the paint industry. In: International symposium on the control of air pollution in the working environment. The work environment fund/ILO, Stockholm 1977, pp 66-75.

16. Vesterberg $\mathrm{O}$, Sollenberg J, Wrangskog K. Evaluation of determinations made in urine samples: Adjustments of mandelic acid concentration using creatinine and density. Ann Am Conf Ind Hyg 12 (1985) 301-304.

Received for publication: 13 December 1985 